\title{
Percepção de Estresse entre Discentes do Curso de Enfermagem de uma IES
}

\author{
Thaís da Silva Moreira ${ }^{1}$; Giovana Fernandes Araújo ${ }^{2}$
}

\begin{abstract}
Resumo: Este estudo teve por objetivo avaliar a percepção de estresse entre estudantes de enfermagem do último semestre de uma Instituição de Ensino Superior (IES) particular, no sudoeste da Bahia. Trata-se de uma pesquisa descritiva, de natureza qualitativa. A coleta de dados foi realizado através de entrevistas com roteiro semiestruturado, no período de 05 a 10 de maio de 2017. Participaram 15 estudantes de enfermagem matriculados no turno vespertino. As entrevistas, após realizadas, foram transcritas para o programa Word/Starter 2010. Os dados foram analisados visando a identificação das categorias e unidades temáticas a partir da utilização do referencial de Bardin. A análise foi ancorada no referencial teórico escolhido. Após apreciação dos dados, emergiram quatro categorias a saber: conceito do estresse; compreensão dos sinais e sintomas do estresse; fatores estressantes percebidos diariamente e fatores estressantes esperados na vida acadêmica e futuro profissional. Os resultados do estudo levam à reflexão de que é preciso que no meio acadêmico haja medidas preventivas ou redutoras de estresses, para que a aprendizagem se efetive de forma satisfatória e os alunos sejam preparados para o enfrentamento dos desafios da profissão.
\end{abstract}

Descritores: Enfermagem; Estudantes de enfermagem; Percepção do estresse.

\section{Perception of Stress among Nursing Students of a Teaching Institution}

\begin{abstract}
This study aimed to evaluate the stress among nursing students in the last semestre of a private teaching istitution in the southwestern region of Bahia. It is a descriptive and qualitative research. The data collection was performed by interviews with semi-structured script, in the period between 05 to 10 of May 2017. 15 nursing students enrolled in the afternoon period participated of the study. The interviews were transcribed into the Word / Starter 2010 program. The data were analyzed aiming the identification of the categories and thematic units from the use of Bardin reference. The analysis was made according to the chosen theoretical reference. After evaluating the data, four categories were highlighted: the concept of stress; Understanding of the signs and symptoms of stress; Stress factors perceived daily and stress factors expected in academic life and professional future. The results of the study lead to the reflection that there must be preventive or stress-reducing measures in the academic world, so that the learning process is satisfactory and students are prepared to face the challenges of the profession
\end{abstract}

Keywords: Nursing; Nursing students; Perception of stress.

\section{Introdução}

Um dos assuntos recorrentes na atualidade, o qual pode interferir diretamente na qualidade de vida do indivíduo, é o estresse. O termo "estresse" tem sua origem na física e nesta tem como definição o nível de deformidade suportada por uma estrutura quando é submetida a um esforço (LIPP, 2009). Tempos depois, o termo passou a ser utilizado pela medicina e

\footnotetext{
${ }^{1}$ Graduanda em Enfermagem pela Faculdade Independente do Nordeste - FAINOR. taimoreiraa@gmail.com>

${ }^{2}$ Mestre em Meio Ambiente e Sustentabilidade -UNEC . giovanafaraujo@ hotmail.com 
biologia, significando empenho do organismo em adaptar-se para enfrentamento de uma situação que avalie como ameaçadora à sua vida e seu equilíbrio interno.

O estresse é uma condição no qual o indivíduo sofre alterações em sua homeostasia, sendo esta responsável em manter uma estabilidade adequada para o equilíbrio do corpo, ou seja, o meio interno. Portanto, estresse é uma condição no qual o indivíduo sofre alterações em sua homeostasia, sendo esta responsável em manter uma estabilidade adequada para o equilíbrio do corpo, ou seja, o meio interno. Quando ocorre a necessidade de adaptação ao meio externo essas mudanças podem alterar o equilíbrio homeostático, com respostas positivas ou negativas (TORTORA; GERARD, 2013). Quando negativo ocorre um desequilíbrio que gera sensação de mal-estar, incapacidade, tristeza, insatisfação, progredindo para doenças patológicas (MENTAL HELP, 2009).

Um dos ambientes que desafiam o equilíbrio homeostático do indivíduo é o universitário, o qual expõe o acadêmico a situações diárias que demandam adaptações e estas por sua vez, podem ser apontadas como estressoras. Ao ingressar na universidade, os estudantes deparam-se com um novo ambiente e compromissos que são, muitas vezes, distintos do seu cotidiano e do ritmo característico do ensino médio (COSTA; POLAK, 2009).

Em meio ao processo de aprendizagem, o acadêmico tem que adaptar-se às obrigações, exigências, disciplinas, cumprimento de prazos, demonstrações de conhecimentos teóricos e práticos, trabalho de conclusão de curso (TCC), que são métodos avaliativos necessários para a sua formação. Portanto, necessitam adequar-se às essas responsabilidades pessoais e exteriores da vida acadêmica, que contribuem para o surgimento de situações estressoras (COSTA; POLAK, 2009). Esse período é marcado por múltiplos fatores que possibilitam alterações no desempenho do discente quanto à capacidade de raciocínio, memorização e interesse em relação ao processo de ensino aprendizagem e o estresse é um deles (TORQUATO, 2015).

Segundo Monteiro, Freitas e Ribeiro (2007) idade, o estado civil, gênero, número de filhos, ter uma ocupação profissional além da acadêmica, meio de transporte utilizado para chegar à universidade, dentre outros, podem levar à maior predisposição para instabilidade emocional no período acadêmico e, consequentemente, mais vulnerabilidade em torna-se um futuro profissional estressado. 
Isto posto, o estudo teve por problema investigado: Qual é a percepção de estresse dos estudantes de enfermagem que cursam o $10^{\circ}$ semestre? Assim, o objetivo geral foi avaliar a percepção de estresse dos discentes do $10^{\circ}$ semestre do curso de enfermagem de uma instituição de ensino superior (IES) particular.

O interesse em realizar este estudo deu-se por observar, através de publicações e estudos discutidos em sala de aula, que a enfermagem está entre as profissões mais estressantes, despertando a curiosidade em investigar a visão do acadêmico de enfermagem sobre estresse.

\section{Metodologia}

Trata-se de um estudo exploratório-descritivo, de natureza qualitativa, tendo como campo de pesquisa uma IES privada localizada no sudoeste da Bahia.

A amostra compreendeu 15 alunos matriculados no $10^{\circ}$ semestre do turno vespertino do curso de Enfermagem. Foram adotados como critérios de inclusão: estudantes regularmente matriculados, que aceitaram participar voluntariamente da pesquisa e assinaram o Termo de Consentimento Livre e Esclarecido-TCLE. Sendo de exclusão: aqueles que não aceitaram participar da pesquisa, não assinaram o TCLE ou estavam de licença por motivo de saúde no período da coleta de dados.

A coleta de dados foi realizada na própria IES, no período de 01 a 10 de maio de 2017, através de entrevista gravada utilizando-se um roteiro semiestruturado elaborado e aplicado pelas pesquisadoras. As entrevistas, após serem realizadas, foram transcritas para o programa Word/Starter 2010. Os participantes da pesquisa foram identificados pela letra A (acadêmico) seguida do número de ordem de participação na pesquisa: A1, A2 e assim sucessivamente. Os dados analisados levaram à identificação das categorias e unidades temáticas a partir da utilização do referencial de Bardin. A análise dos dados foi operacionalizada a partir das seguintes ações: primeiro foi realizada a leitura flutuante e aprofunda dos dados grifando os relatos significativos, semelhantes e diferentes; recortes de fragmentos grifados; busca de categorias a partir das temáticas que emergiram; elaboração de uma lista de fala dos entrevistados por categorias; escolha das falas com maior poder de síntese e abrangência, informações dentre os conteúdos das entrevistas para exemplificar as categorias emergentes. A 
análise foi ancorada no referencial teórico escolhido. Na descrição da população pesquisada, foram apresentados dados em números absolutos e porcentagem.

O estudo foi aprovado pelo Comitê de Ética da Faculdade Independente do Nordeste, cujo protocolo foi CAE 66053417.3.0000.5578, obedecendo à Resolução 466/12 do Conselho Nacional de Saúde.

\section{Resultados e Discussão}

A população estudada foi composta por 15 estudantes concluintes do curso de enfermagem. Compreendeu a faixa etária de 21 a 62 anos, sendo a maior concentração de estudantes com de 23 a 34 anos (60\%). Houve a predominância absoluta do sexo feminino $15(100 \%)$, lembrando que a enfermagem ainda é hegemonicamente constituída por mulheres, de acordo com (COFEN, 2015).

Em relação à outra formação profissional, apenas 3 (20\%) possui curso técnico em enfermagem, as quais exercem suas funções em unidades hospitalares. Uma parcela dos estudantes trabalham 6 (40\%), seguida de 9 (60\%) que não possui outra ocupação profissional. Os dados mostraram que 14 (93\%) da população são residentes do município onde está a IES e 1(3\%) em outro município.

Pode-se destacar no perfil a idade de uma das participantes, pois fazia parte da faixa acima de 60 anos. Estudos tem mostrado a busca por idosos por novos conhecimentos e qualificação para o mercado de trabalho (IBGE, 2015).

A partir da análise das respostas emergiram quatro categorias a saber: 1- Conceito do estresse; 2- Compreensão dos sinais e sintomas do estresse; 3 - Fatores estressantes percebidos diariamente e 4- Fatores estressantes esperados na vida acadêmica e futuro profissional.

\section{Conceito do estresse}

No que refere ao conceito de estresse, foi possível identificar que os estudantes, em sua grande maioria, não possui conhecimento teórico-cientifico sobre a concepção do que seja 
realmente estresse. Este foi confundido com sinais e sintomas e situações que podem causar estresse ou gerar estresse, conforme as falas descritas abaixo:

[...]Eu entendo como uma doença, que está, tipo que está destruindo a humanidade, que causa violências é isso ai. (A11)

[...]É um nível alto de responsabilidade e excesso de trabalho, sobrecarga de trabalho é o que mais gera o estresse, muita responsabilidade né? (A 8)

[...]Estresse pra mim é: nervosismo, irritabilidade, desequilibro emocional, essas coisas assim ... (A 6)

Contudo, uma pequena parcela das participantes do estudo, apresentou algum conhecimento acerca do tema discutido, conforme os relatos a seguir:

[...]Estresse é a forma física e emocional de como o corpo reage algum tipo de pressão. (Número 12)

[...]Pra mim estresse é quando você está em um ápice de uma situação vivenciada ali, onde o seu corpo começa apresentar resposta, frente aquilo que você está fazendo. Então você apresenta mal estar, você apresenta forte dores de cabeça, por conta da sobrecarga que está vindo sobre você. (A7)

[...] Estresse é tudo aquilo que te tira da zona de conforto, levando a não adaptação a uma situação. (A 15)

De acordo com Lipp (2009) o estresse caracteriza-se por reações do organismo quando o indivíduo é exposto situações que geram instabilidade na homeostasia do meio interno e exigem esforço de adaptação e a emissão de vários comportamentos e estratégias adequadas ou não de enfrentamento, para preservar o bem-estar e a vida. Que envolve reações físicas, psicológicas, mentais e hormonais frente a qualquer evento que seja interpretado como desafiador.

De acordo com Oliveira (2009), em 1936, Hans Selye formalizou o conceito de estresse. Chamou de síndrome geral de adaptação às três fases do estresse: a reação de alarme, o estado de resistência e o estado de exaustão. A reação de alarme é a primeira reação do corpo diante de uma agressão e é marcada por uma descarga de adrenalina, pelas pulsações cardíacas, pelas mudanças no tônus muscular e na circulação sanguínea. Na segunda fase, ou estado de resistência, o organismo, após a reação de alarme, procura se adaptar e resistir à agressão. A terceira fase, ou estado de exaustão, ocorre quando a agressão se prolonga por um período maior, fazendo com que a pessoa perca as energias e a sua força adaptativa. 


\section{Compreensão dos sinais e sintomas do estresse}

Ao analisar essa temática, as entrevistadas apontaram desde os sinais e sintomas psicológicos tais como insônia e irritabilidade, até a progressão para o físico como alterações no peso e outras patologias:

[...] Pra mim é palpitações, que nem sempre está relacionado ao estresse, mas as vezes pode ser o estresse, cansaço, dorme e acorda cansada, você se chateada por pouca coisa, tem uma irritabilidade muito grande, o que mais eu posso colocar, tipo assim fica muito emotiva, tem gente que fica muito emotiva, chorando, tem tremores na face, tremores nos olhos, mais ou menos isso. (A5)

[...]Pode acontecer de no meu entendimento várias situações de sintoma de estresse, como por exemplo: irritabilidade, pode acontecer alterações do sono, seja insônia ou excesso de sono, pode acontecer também em várias situações de estresse, questões físicas como a gente percebe de peso, ou aumento ou diminuição, dentre outros. (A 9)

[...]Insônia é um deles, eu acho que a insônia é o sinal de alerta, quando você estar estressado, e ai tem uma series de coisas, seu corpo começa a ter, vai para o físico e você começa a ter dores realmente. Eu por exemplo, tive momento de estresse que desencadeou uma crise de hérnia de disco, começou, usar medicamentos, o uso da medicação me levou a uma crise hipertensiva, pelos corticoides, então o estresse leva a essas coisas. Ele sai do emocional e leva para o físico, no meu caso já aconteceu isso. (A 10)

Um dos sinais e sintomas psicológico do estresse mais citados entre as entrevistadas foi a alteração no sono, como a insônia. Segundo Albuquerque (2016), o sono, de modo geral, é essencial para o repouso do corpo e da mente, sendo o período em que o organismo é totalmente restaurado, devido às energias gastas ao longo do dia. Como o sono é essencial para promover o equilíbrio no organismo, havendo seu comprometimento, desencadeia o aparecimento problemas físicos ao indivíduo.

Segundo Seleghim (2012), diferentes sinais e sintomas de estresse apresentam-se em cada fase: na de alarme, quando o indivíduo reconhece o estimulo estressor, e o organismo pode apresentar o aumento de sudorese, taquipneia, taquicardia, entusiasmos súbito, entre outros. Na segunda fase, a resistência, o organismo busca o retorno do seu reequilíbrio, surge problema de memória, mudança de apetite, cansaço constante, problemas dermatológicos, tonturas, irritabilidade excessiva, diminuição no libido, entre outros. Na terceira, exaustão, já ocorre comprometimento físico e psíquico, tais como ansiedade, insônia, raiva, hipertensão, depressão entre outros. 


\section{Fatores estressantes percebidos diariamente}

O estudo apontou que as responsabilidades pessoais, ocupação profissional juntamente com a vida acadêmica, em sua maioria, são fatores que podem sobrecarregar os estudantes e contribuir com que os mesmos atinjam um desgaste físico ou psicológico. Como pode ser observado nos relatos abaixo:

[...]E o trabalho porque é correria mesmo, sai do trabalho, vem para faculdade, não almoço direito, o que me mata é isso, não tem um lanche da tarde, da manhã, o almoço não faz direito, as horas de sono. O tempo que é muito corrido no dia a dia, trabalho, faculdade, e ai acaba gerando estresse da correria do dia a dia, da alimentação que acaba não saindo certo também, das horas de sono que acabam não sendo adequadas por conta de trabalhos que tem que ser feitos durante a noite, dentre outras coisas... (A 3)

[...]Faculdade, é com certeza, a faculdade é a questão do trabalho, porque como na maioria dos estudantes que trabalham, tem a questão do trabalho e vai direto para faculdade, então tem toda esse responsabilidade, e com esposo, dona de casa, tenho meus afazeres em casa, então esse tempo que eu não tenho para descansar, minha mente anda cansada, meu corpo também, então é o que eu mais convivo justamente esse questão, de faculdade é responsabilidades que eu tenho, trabalho e casa. (A 8)

[...]A sobrecarga do dia literalmente, da rotina. Porque eu trabalho e estudo, e ai moro em outra cidade né? Ai eu trabalho e moro em uma cidade e estudo em outra, então isso pra mim já acaba sendo um fator de estresse enorme, o tempo curto para desenvolver minhas atividades do dia a dia. Além de não poder da atenção e cuidar das minhas duas filhas. Fico triste em ser muitas vezes mãe ausente. Por mais difícil que seja, faço esse sacrifico para o futuro delas e agora concluindo a faculdade ficarei feliz e poder me dedicar mais como mãe presente de fato. (A 9)

Segundo Araújo (2009, p. 48), "o trabalho parece ter invadido todos os poros da vida, ocupando parte do tempo e das preocupações do trabalhador". A adequação ao meio acadêmico, as atividades impostas no período de graduação, associados ao trabalho ocupacional, proporcionam desafios aos estudantes trabalhadores devido ao tempo, que em muitas situações é insuficiente para que os mesmos possam dedicar-se de forma mais aplicada a vida acadêmica (ARAUJO, 2009).

Outro fator que podemos associar como desafio pelas estudantes, é a conciliação da vida acadêmica com a maternidade. Segundo Glat (2009), a terceira etapa pós-maternidade é quando a mulher passa a se organizar para retornar ao convívio social e profissional. E esse retorno, como a exemplo da vida acadêmica, quando não organizada, pode promover insatisfação pessoal, devido à redução no convívio com os filho(s). 
Para Bruschini (2007), a mulher ao longo dos anos conquistou seu espaço no mercado de trabalho, contudo perpetua-se o antigo modelo tradicional familiar, sendo responsáveis também pelos cuidados domésticos. Esses cuidados, juntamente com dupla jornada (trabalho e filhos) ou tripla jornada (trabalho, estudo e filhos), são elementos que dificultam a atividade produtiva da mulher atualmente, os quais podem favorecer ao estresse.

\section{Fatores estressantes esperados na vida acadêmica e futuro profissional}

Ao serem questionadas sobre os fatores estressantes relacionados à faculdade e à sua futura vida profissional foram mencionadas as atividades avaliativas, como os trabalhos acadêmicos, a semana de provas e a elaboração do Trabalho de conclusão de curso (TCC):

[...]Relacionado a faculdade eu vejo a elaboração do TCC, que tem uma dificuldade bastante intensa no momento, a falta de comprometimento de alguns dos nossos superiores, não em relação ou TCC. (A 1)

[...]É a faculdade, pelo...pelo, trabalhos, são muitos trabalhos que a gente tem que virar a noite fazendo, é não dá tempo de fazer tudo na faculdade, nem estudar ainda...exatamente. (A 3)

[...]Bom, a faculdade o que mais me deixa estressante é a avaliação, acho que avaliação que é feita, talvez seja pela minha própria idade, e já com 62 anos em uma faculdade, eu acho que isso me estressou muito, essa avaliação, essa avaliação escrita então, essas avaliações elas não mostram o profissional que vai ser, acho que deveria ter uma outra maneira de avaliações. (A10)

Esses relatos corroboram com os encontrados no estudo realizado por Silva (2011) com estudantes do último semestre de enfermagem, os fatores estressantes relacionado a faculdade são semelhantes. Essa adaptação ao universo acadêmico até a conclusão da graduação, geram muitas vezes, circunstancias desafiadoras, e o estudante pode apresentar dificuldades para adequá-la. Refletindo na qualidade de vida e no desempenho acadêmico, ficando frustrados, irritados, ansiosos, devido as situações estressoras vivenciadas.

Sobre os fatores estressantes que podem ser vivenciados na vida profissional as participantes classificaram a sobrecarga física e psicológica como o principal fator, devido à má remuneração, jornada dupla de trabalho e responsabilidade em lidar com vidas: 
considerada muito estressante, isso por conta da sobrecarga de trabalho, a responsabilidade por tá lidando com vida de pessoas, e acho que vai ser um grande desafio, mas estamos ai, pra tentar lidar com eles da melhor forma possível, e tentando de alguma maneira fazer com que esse dias e esse trabalho sejam menos estressantes né? E é isso. (A 5)

[...]E em relação ao serviço mesmo, a gente sabe que, o profissional na área de saúde ele não é muito bem remunerado, ele necessita fazer várias cargas horarias né? Trabalhar em vários locais, e justamente por conta disso, tem essas sobrecargas, então é um dos fatores principais que a gente pode estar observando, que os profissionais da área da saúde vem adoecendo justamente por isso, está sobrecarga de trabalho, então a cobrança porque tá lindando com saúde, com paciente, você tem uma responsabilidade muito maior, então, e principalmente na área da enfermagem, que você não cuida apenas do físico, o enfermeiro ele também é um psicólogo, então ele vê um paciente como um todo, então todo esse meio que o profissional de saúde tá envolvido, é de um estresse né? Porque é uma responsabilidade grande, um erro, a gente sabe que pode pagar pelo resto da vida, se trata de vidas, de pessoas que está ali na sua mão, então é um dos fatores que acho muito importante a ser observado esse questão da sobrecarga de trabalho. (A 8)

[...]E em relação a futura vida profissional como enfermeiro, a gente vê que questão da sobrecarga de trabalho, e lidar com o sofrimento do outro pode lhe gerar uma sobrecarga enorme e gerar um estresse, porque você como profissional de enfermagem, geralmente você não vai estar encontrando pessoas sadias para você está batendo um papo, você vai estar encontrando na maioria das vez pessoas doentes, então você lidando com prevenção de doença, ou a parte curativa de doença, então você também pode tá desenvolvendo ai estresse na vida profissional, a sobrecarga de trabalho vem mais por conta da desvalorização financeira do profissional que acaba por si só, procurando dois ou três empregos para valer a pena financeiramente trabalhar na área. (A 9)

Segundo Lima (2013), baixos salários na área da enfermagem, tornam-se insuficientes para o sustento pessoal e, principalmente, familiar. Em busca de novas fontes de renda, os trabalhadores se submetem a dupla ou mais jornadas de trabalho. Vários vínculos empregatícios podem interferir na qualidade de vida do enfermeiro por questões como a falta de tempo para descansar, a sobrecarga de tarefas, a frustação pela falta de qualificação profissional, a ausência do convívio familiar e lazer.

Para Dos Santos (2011) é preciso reconsiderar as políticas públicas, na esfera trabalhista, empregadas na área da saúde, não somente relacionadas à redução da carga horária de trabalho, como também a valorização profissional através de melhor remuneração. Essas mudanças podem contribuir diretamente na redução de agentes estressores que levam ao desgaste físico e emocional do enfermeiro, melhorar a qualidade de vida do profissional e, consequentemente, a assistência prestada ao paciente. 
Apesar dos fatores desafiantes referentes à futura carreira, algumas estudantes sentemse realizadas em concluir o curso, dispostas a enfrentar os desafios, e atingir a satisfação pessoal e profissional, conforme descrito abaixo:

[...]Sobre minha vida profissional, eu creio, apesar dos pesares, vai ser positivo pra minha vida, porque apesar do estresse, de todo cansaço, de tudo que foi cobrado na faculdade, vai me acarretar ser uma profissional que busca, que tem objetivos e busca, e vai passar essa fase da faculdade e eu sei que vai ser melhor, eu acho que vou conseguir lidar melhor com as situações que a vida vai me proporcionar. (A 5)

[...]Já em relação ao meu futuro profissional, eu sei que o desafio vai ser muito grande, mas eu tenho que estar preparada para isso, pois a minha profissão e considerada muito estressante, isso por conta da sobrecarga de trabalho, a responsabilidade por tá lidando com vida de pessoas, e acho que vai ser um grande desafio, mas estamos ai, pra tentar lidar com eles da melhor forma possível, e tentando de alguma maneira fazer com que esse dias e esse trabalho sejam menos estressantes né? E é isso. (A 7)

[...]Bom, minha futura vida profissional é aposentadoria mesmo, essa graduação é mais uma realização de sonho, pode ocorrer trabalhar mais um ano ou dois anos, mas não na assistência, mais numa parte administrativa, da qual eu espero fazer uma pós em uma parte administrativa, agora assistência não. (A 10)

Para Silva (2010), a transição de acadêmicas para profissionais de enfermagem é percebida como um momento desafiador e de muitas descobertas. Esses momentos podem ser positivos pela possibilidade em proporcionar satisfação, entusiasmo e realização, ou negativos por surgirem frustrações, insegurança e descontentamento profissional.

Conforme um estudo realizado por Melo (2011), a satisfação no trabalho influencia diretamente na qualidade de assistência da enfermagem. Essa satisfação reincide no bem-estar do profissional e do paciente assistido por ele. A enfermagem é intitulada como a arte do cuidar, em que a demonstração de afeto, reconhecimento e gratidão por parte dos mesmos. O tipo de relacionamento terapêutico pode minimizar os fatores estressantes.

\section{Considerações Finais}

A partir desse estudo pôde-se concluir que as estudantes do último semestre de enfermagem, em sua maioria, não possui conhecimento teórico sobre a definição de estresse. Entretanto, compreendem os sinais e sintomas físico e psicológico que o estresse pode 
desencadear e a sua progressão para doenças crônicas. Também foi possível identificar os fatores estressantes vivenciados pelas estudantes em sua vida pessoal e acadêmica, bem como as expectativas relacionadas ao futuro profissional, segundo sua percepção.

Os resultados do estudo levam à reflexão de que é preciso que no meio acadêmico haja medidas preventivas ou redutoras de estresses, para que a aprendizagem se efetive de forma satisfatória e os alunos sejam preparados para o enfrentamento dos desafios da profissão.

\section{Referências}

ALBUQUERQUE, Alfredo Armindo Figueiredo de. Qualidade do sono e trabalho por turnos. 2016. Tese de Doutorado.

ARAÚJO, S. M. et al. Sociologia: um olhar crítico. São Paulo: Contexto, 2009.

BRUSCHINI, Maria Cristina Aranha. Trabalho e gênero no Brasil nos últimos dez anos. Cadernos de Pesquisa, São Paulo, v.37, n.132, Set./Dec. 2007. Disponível em: < http://www.scielo.br/> Acesso em: 20 maio. 2017.

BRASIL. Conselho Federal de Enfermagem - COFEN. Pesquisa inédita traça perfil da enfermagem. 2015. Disponível em: < http://www.cofen.gov.br/>. Acesso em: 21 maio. 2017.

COSTA, Ana Lucia Siqueira; POLAK, Catarina. Construção e validação de instrumento para Avaliação de Estresse em Estudantes de Enfermagem (AEEE). Rev. esc. enferm. USP, São Paulo, v. 43, n. spe, p. 1017-1026, Dec. 2009.

DE MELO, Márcia Borges; BARBOSA, Maria Alves; DE SOUZA, Paula Regina. Satisfação no trabalho da equipe de enfermagem: revisão integrativa. Revista Latino-Americana de Enfermagem, v. 19, n. 4, p. 1047-1055, 2011.

DA SILVA, Denise Guerreiro Vieira et al. Os desafios enfrentados pelos iniciantes na prática de enfermagem. Revista da Escola de Enfermagem da USP, v. 44, n. 2, p. 511-516, 2010.

DOS SANTOS, Taciana Mirella Batista; DA SILVA FRAZÃO, Iracema; FERREIRA, Delmilena Maria Aquino. Estresse ocupacional em enfermeiros de um hospital universitário. Cogitare Enfermagem, v. 16, n. 1, 2011.

GLAT, R. Ser mãe e viva a vida. Rio de Janeiro: Documenta Histórica Editora, 2009.

GOTO, André Kenreo; SOUZA, Maria Tereza Saraiva de; LIMA JUNIOR, José Vianna. Um estudo sobre o estresse em profissionais da área de logística da indústria automobilística. Rev. psicol. polít., São Paulo, v. 9, n. 18, p. 291-311, dez. 2009 . 
IBGE - Instituto Brasileiro de Geografia e Estatística. Estatística da População. 2007. Disponível em: <www.ibge.gov.br/ >. Acesso em 19 maio 2017.

LIMA, B.M. Agentes estressores em trabalhadores de enfermagem com dupla ou mais jornada de trabalho. Rio de Janeiro, v. 5, n.1, jan./mar. 2013. Disponível em <http://biblioteca.cofen.gov.br/>. Acesso em: 15 maio. 2017.

MENTAL Help - Stress Reduction and Management Types of Stressors (Eustress vs. Distress. Disponível em: <http://www.mentalhelp.net/>. Acesso em 15 maio 2017.

LIPP, M.E.N. Stress: conceitos básicos. In M.E.N. Lipp (Org.). Pesquisas sobre stress no Brasil. Saúde, ocupações e grupos de risco. Revista de Psicologia da IMED, Campinas: Papirus. 2009.vol.1, n.1, p. 114-126.

MONTEIRO, C. F. de S.; FREITAS, J. F. de M.; RIBEIRO, A. A. P. Estresse no Cotidiano dos Alunos de Enfermagem da UFPI. Escola Anna Nery Revista Enfermagem, v. 1, n. 11, p. 66 $-72.2007$.

SILVA VLS, Chiquito NC, Andrade RAPO, Brito MFP, Camelo SHH. Fatores de estresse no último ano do Curso de Graduação em Enfermagem percepção dos estudantes. Rer. Enfer. UERJ. 2011; 19 (1): 121-6

TELLES FILHO, P. C. P.; PIRES, E.; ARAUJO, G. A. Características evidenciáveis de estresse em discentes de enfermagem. Revista Latino- Americana Enfermagem, Ribeirão Preto, v. 7, n. 2. p. 91-93.1999.

TORQUATO, Jamili Anbar et al. Avaliação do estresse em estudantes universitários. InterSciencePlace, v. 1, n. 14, 2015.

TORTORA, Gerard J. Princípios de anatomia humana / Gerard J. Tortora, Mark T. Nielsen; Rio de Janeiro: Guanabara Koogan, 2013.

\section{Questionário}

\section{1- Questões Sócios Culturais}
A) Sexo:
B) Idade:
C) Possui Outra Formação?
D) Trabalha? 
Id on Line Revista Multidisciplinar e de Psicoloqia

Id on Line Multidisciplinary and Psycology Journal

E) Se Trabalha, quantas horas por dia?

F) Reside Em Vitória da Conquista?

\section{2- Roteiro de Entrevista Semi Estruturada}

A) O que você entende por estresse?

B) Quais são os sinais e sintomas de estresse em seu entendimento?

C) Quais são os fatores de estresse vivenciados por você no seu dia a dia?

D) Descreva os fatores estressantes relacionados à faculdade e à sua futura vida profissional.

Como citar este artigo (Formato ABNT):

MOREIRA, Thaís da S.. ARAÚJO, Giovana F.. Percepção de Estresse entre Discentes do curso de Enfermagem de uma IES. Id on Line Revista Multidisciplinar e de Psicologia, Maio de 2017, vol.11, n.35, p. 479-491. ISSN: 1981-1179.

Recebido: 28.05.2017

Aceito: 29.05.2017 